\title{
Association between body composition and conformity to the recommendations of Canada's Food Guide and the Dietary Approaches to Stop Hypertension (DASH) diet in peri-adolescence
}

\author{
Samantha Hajna ${ }^{1}$, Jian Liu ${ }^{1, *}$, Paul J LeBlanc ${ }^{1}$, Brent E Faught ${ }^{1}$, Anwar T Merchant ${ }^{2}$, \\ John Cairney ${ }^{3,4}$ and John Hay ${ }^{1}$ \\ 'Department of Community Health Sciences, Brock University, 500 Glenridge Avenue, St. Catharines, \\ Ontario, Canada, L2S 3A1: 'Department of Epidemiology and Biostatistics, Arnold School of Public Health, \\ University of South Carolina, Columbia, SC, USA: ${ }^{3}$ Department of Family Medicine, McMaster University, \\ Hamilton, Ontario, Canada: ${ }^{4}$ Department of Psychiatry \& Behavioural Neurosciences, McMaster University, \\ Hamilton, Ontario, Canada
}

Submitted 4 June 2011: Final revision received 13 December 2011: Accepted 24 February 2012: First published online 17 April 2012

\begin{abstract}
Objective: The role of following the recommendations of Canada's Food Guide (CFG) and the Dietary Approaches to Stop Hypertension (DASH) diet on body composition in children is unknown. The present study assessed how conformity to the recommendations of these diets was associated with BMI, waist-to-height ratio (WHtR), waist-to-hip ratio (WHR), waist girth (WG), hip girth (HG) and risk of overweight in peri-adolescents.

Design: CFG and DASH indices were derived from responses to a food questionnaire, with a higher index representing greater conformity to CFG and DASH diet recommendations. Body composition was assessed by trained research assistants. Setting: Schools within the Niagara region (Ontario, Canada).

Subjects: Children ( $n$ 1570) aged $12 \cdot 4$ (SD 0.3) years.

Results: After adjustment for age to peak height velocity and total physical activity, a higher CFG index was associated with lower WHtR $(b=-0 \cdot 001,95 \% \mathrm{CI}-0 \cdot 002$, $-0 \cdot 0004)$, WHR $(b=-0 \cdot 001,95 \%$ CI $-0 \cdot 002,-0 \cdot 001)$ and WG $(b=-0 \cdot 18,95 \%$ CI $-0 \cdot 30,-0 \cdot 07)$ in girls. No associations were observed in boys. In contrast, a higher DASH index was associated with decreased body composition measures in both genders. Specifically, the DASH index was negatively associated with BMI (girls: $b=-0 \cdot 07,95 \%$ CI $-0 \cdot 10,-0 \cdot 04$; boys: $b=-0 \cdot 05,95 \%$ CI $-0 \cdot 08,-0 \cdot 02)$, WHtR (girls: $b=-0 \cdot 001,95 \%$ CI $-0 \cdot 002,-0 \cdot 001$; boys: $b=-0 \cdot 001,95 \%$ CI -0.002 , $-0 \cdot 0004$ ), WHR (girls: $b=-0 \cdot 001,95 \%$ CI $-0 \cdot 002,-0 \cdot 001$; boys: $b=-0 \cdot 001,95 \%$ CI $-0 \cdot 001,-0 \cdot 00004$ ), WG (girls: $b=-0 \cdot 24,95 \%$ CI $-0 \cdot 31,-0 \cdot 16$; boys: $b=-0 \cdot 15,95 \% \mathrm{CI}-0 \cdot 24,-0 \cdot 07$ ) and HG (girls: $b=-0 \cdot 15,95 \% \mathrm{CI}-0 \cdot 23,-0 \cdot 07$; boys: $b=-0 \cdot 12,95 \% \mathrm{CI}-0 \cdot 19,-0 \cdot 04)$. A higher DASH index was also associated with lower odds of overweight in girls $(\mathrm{OR}=0 \cdot 70,95 \% \mathrm{CI} 0 \cdot 56,0 \cdot 87)$ and boys $(\mathrm{OR}=0 \cdot 76,95 \%$ CI $0 \cdot 62,0 \cdot 93)$.

Conclusions: The DASH diet may prevent overweight in peri-adolescents.
\end{abstract}

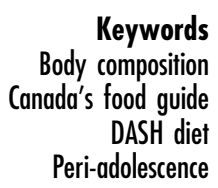

In Canada, approximately $30 \%$ of children are overweight or obese (OW/OB), representing more than a doubling in prevalence over the past three decades ${ }^{(1,2)}$. Children who are OW/OB are at increased risk for serious long-term health complications including insulin resistance, type 2 diabetes, vascular disease, osteoarthritis and various forms of cancers ${ }^{(1,3,4)}$. In order to optimize child health and to reduce financial burden associated with the treatment of OW/OB-related complications, prevention and treatment of OW/OB should become public health priorities $^{(5,6)}$.

Diet is a major determinant of childhood $\mathrm{OW} / \mathrm{OB}^{(5)}$. The main source of information for healthy eating in Canada is the Eating Well with Canada's Food Guide (CFG), the primary objective of which is the maintenance of population health ${ }^{(7,8)}$. Another widely referenced diet, albeit within clinical settings, is the Dietary Approaches to Stop Hypertension (DASH) diet, an initiative of the 
National Heart, Lung, and Blood Institute ${ }^{(9,10)}$. The primary purpose of the DASH diet is the treatment and management of hypertension ${ }^{(9)}$. Neither CFG nor the DASH diet has been designed exclusively for the prevention and/or treatment of OW/OB. However, since adherence to the DASH diet has been linked in adults to improved body weight and decreased hypertension ${ }^{(11,12)}$, a common complication of $\mathrm{OW} / \mathrm{OB}^{(13)}$, it is hypothesized that the DASH diet may be more effective in reducing OW/OB than CFG. Aside from the DASH diet's focus on reduced sodium intake ${ }^{(9)}$, its emphasis on fruit and vegetable intake ${ }^{(14-16)}$ may reduce hypertension via a reduction in weight. Despite the pressing concerns of childhood OW/OB, few studies have assessed the impact of following the CFG recommendations and the DASH diet on measures of adiposity in youth. The aim of the present study was to assess how conformity to the recommendations of each of these diets was associated with BMI, waist-to-height ratio (WHtR), waist-to-hip ratio (WHR), waist girth (WG), hip girth (HG) and risk of OW in peri-adolescent boys and girls.

\section{Methods}

Data were collected between September 2007 and June 2008 on 2304 children recruited from schools within the Niagara region. After cleaning for missing information related to the present study, data on a total of 1570 (68.1\%) children (mean age 12.39 (SD 0.33) years; 782 girls; 788 boys) were available for analysis. Prior to data collection, ethics approval was obtained from Brock University's Research Ethics Board and the District School Board of Niagara's Research Committee.

Body composition was assessed during school hours by trained research assistants using standard protocols. Participants wore clothing required for light physical activity (PA) and no footwear. Weight and height were measured using a Tanita electronic weight scale and a Seca portable stadiometer, respectively. WG was measured at the umbilicus and HG was measured around the widest portion of the buttocks using a flexible measuring tape. Each measure was recorded three times and the average of these three measures was calculated. All values were recorded to the nearest $0.1 \mathrm{~kg}$ or $0.1 \mathrm{~cm}$. Weight, height, WG and HG were used to calculate BMI, WHtR and WHR. Students were categorized into OW or non-OW groups using gender- and age-specific BMI cut-offs ${ }^{(17)}$.

The degree to which children's diets conformed to the recommendations of $\mathrm{CFG}$ and the $\mathrm{DASH}$ diet were quantified using two indices that were calculated based on responses provided to the Youth/Adolescent Questionnaire (YAQ), an FFQ previously validated for use in peri-adolescent children ${ }^{(18,19)}$. The YAQ was administered and completed in participants' classrooms during regular school hours.
The DASH index was derived using methods described previously ${ }^{(20-22)}$. The CFG index was derived using a method tailored to the specifications of the CFG. In brief, each response to the YAQ was categorized into one of the eight food groups (fruits, vegetables, grains, dairy, meat/fish/eggs, legumes/nuts/seeds, oils/fats, sweets) for the calculation of the DASH index or one of six food groups (vegetables/fruits, grain products, milk alternatives, meat alternatives, oils/fats, sweets) for the calculation of the CFG index. For each food group, a maximum score of 10 was assigned if the recommended intake was met according to the CFG and the DASH diet. Intakes below the recommended level were scored proportionally less. For food groups where a lower intake was recommended, reverse scoring was applied and a score of 0 was assigned for intakes $\geq 200 \%$ of the upper recommended limit. The scores of each food group were summed to produce final CFG and DASH indices, where a higher index was indicative of greater conformity to the dietary recommendations of the CFG and the DASH diet, respectively. For a more detailed explanation of how each index was calculated, refer to Supplementary Materials.

The covariates assessed in the present study included gender, age, total PA and age to peak height velocity (aPHV). Gender and date of birth were self-reported. Age was calculated using date of birth. Total PA was a scored self-report measure derived from responses provided to the Participation Questionnaire (PQ) ${ }^{(23)}$. aPHV, a genderspecific measure of maturity, was calculated using the anthropometric measures that were collected by the trained research assistants, as per the methods of Mirwald et $a l^{(24)}$. As with all of the other variables of interest, data on covariates were collected from participants during regular school hours.

Early life experience data were collected on a subsample of children. Birth order $(1 v .>1)$ was assessed as part of the PQ and maternal BMI (derived from selfreported weight and height), maternal education ( $\leq$ high school $v$. $\geq$ college) and family living status (single- $v$. two-parent household) were assessed using a parental questionnaire that was sent home with each participant and returned to the school upon completion. Of the 1570 children available for the main analyses, 616 children (321 boys; 295 girls) had no missing information of early life experiences and were available for the sub-sample analyses.

Analyses were performed using the SAS statistical software package version 9.2 (SAS Institute Inc., Cary, NC, USA). Differences in means/proportions were tested between boys and girls using Student $t$ tests and Fisher exact tests. Multivariable linear and logistic regression analyses were used to assess the relationship between the CFG and DASH indices and BMI, WHtR, WHR, WG, HG and risk of OW. Three models were implemented in all analyses. Model 1 was unadjusted, Model 2 was adjusted for aPHV and Model 3 was further adjusted for total PA. 
A fourth model was conducted for the sub-sample of children on whom early life experience data were collected. In addition to adjusting for aPHV and total PA, this model was further adjusted for birth order, maternal BMI, maternal education and family living status.

\section{Results}

Approximately $29 \%$ of girls and $32 \%$ of boys were classified as OW. Boys were slightly older, less mature and had larger WHtR, WHR and WG and smaller HG compared with girls (Table 1).

In girls, all models, except for Model 4, showed that the CFG index was negatively associated with WHtR, WHR and WG (the parameter estimates from Model 3 were $b=-0 \cdot 001,95 \% \mathrm{CI}-0 \cdot 002,-0 \cdot 0004$ for WHtR, $b=-0 \cdot 001$, $95 \%$ CI $-0.002,-0 \cdot 001$ for WHR and $b=-0 \cdot 18,95 \%$ CI $-0 \cdot 30,-0 \cdot 07$ for WG). Although in girls a higher CFG index was also associated with decreased BMI (Models 1 and 2), decreased HG (Model 1) and decreased risk of OW (Model 1), these associations were not observed after further adjustment. In boys, no associations were observed between the CFG index and measures of body composition or risk of OW (Tables 2 and 3).

Similarly, the DASH index in girls was negatively associated with BMI $(b=-0 \cdot 07,95 \%$ CI $-0 \cdot 10,-0 \cdot 04)$, WHtR $(b=-0.001,95 \%$ CI $-0.002,-0 \cdot 001)$, WHR $(b=-0 \cdot 001,95 \% \mathrm{CI}-0 \cdot 002,-0 \cdot 001), \mathrm{WG}(b=-0 \cdot 24$, $95 \% \mathrm{CI},-0 \cdot 31,-0 \cdot 16), \mathrm{HG}(b=-0 \cdot 15,95 \% \mathrm{CI}-0 \cdot 23$, $-0 \cdot 07)$ and odds of OW (OR $=0 \cdot 70,95 \%$ CI $0 \cdot 56,0 \cdot 87)$ after adjustment for aPHV and total PA (Model 3). These associations remained even after further adjustment for the early life experience data that were collected on the sub-sample of children (Model 4), except for HG and odds of OW for which the $P$ values did not reach statistical significance. In boys, however, a higher DASH index was also associated with lower values of BMI $(b=-0 \cdot 05$, $95 \%$ CI $-0 \cdot 08,-0 \cdot 02)$, WHtR $(b=-0 \cdot 001,95 \%$ CI $-0 \cdot 002,-0 \cdot 0004)$, WHR $(b=-0 \cdot 001,95 \%$ CI $-0 \cdot 001$, $-0 \cdot 00004)$, WG $(b=-0 \cdot 15,95 \% \mathrm{CI}-0 \cdot 24,-0 \cdot 07)$ and HG $(b=-0 \cdot 12,95 \% \mathrm{CI}-0 \cdot 19,-0 \cdot 04)$ and lower odds of OW (OR $=0 \cdot 76,95 \%$ CI $0 \cdot 62,0 \cdot 93)$ after adjustment for aPHV and total PA (Model 3). With further adjustment for early life experiences, the association between a higher DASH index and a lower WG and lower odds of OW remained (Tables 4 and 5).

\section{Discussion}

The findings of the present study indicate that a higher CFG index derived from the YAQ was associated with reduced WHtR, WHR and WG in girls only; whereas a higher DASH index was associated with reduced BMI, WHtR, WHR, WG and HG and lower odds of OW in both girls and boys. In the

Table 1 Characteristics of the boys and girls who were recruited from schools within the Niagara region and assessed between September 2007 and June 2008

\begin{tabular}{|c|c|c|c|c|c|}
\hline & \multicolumn{2}{|c|}{ Boys ( $n 788)$} & \multicolumn{2}{|c|}{ Girls ( $n$ 782) } & \multirow[b]{2}{*}{$P$ value } \\
\hline & Mean & SD & Mean & SD & \\
\hline Age (years) & $12 \cdot 41$ & 0.33 & $12 \cdot 37$ & $0 \cdot 32$ & * \\
\hline DASH index (range 0-80) & $52 \cdot 60$ & $8 \cdot 77$ & $52 \cdot 59$ & 8.95 & NS \\
\hline CFG index (range 0-60) & $42 \cdot 90$ & $6 \cdot 01$ & $42 \cdot 87$ & $6 \cdot 17$ & NS \\
\hline \multicolumn{6}{|l|}{ Body composition measures } \\
\hline BMl $\left(\mathrm{kg} / \mathrm{m}^{2}\right)$ & $20 \cdot 37$ & $4 \cdot 11$ & $20 \cdot 32$ & $4 \cdot 16$ & NS \\
\hline Waist-to-height ratio & 0.47 & 0.07 & 0.46 & 0.06 & * \\
\hline Waist-to-hip ratio & 0.93 & 0.07 & 0.90 & 0.06 & $\star * * *$ \\
\hline Waist girth $(\mathrm{cm})$ & $72 \cdot 28$ & $11 \cdot 45$ & $70 \cdot 97$ & $10 \cdot 66$ & * \\
\hline Hip girth $(\mathrm{cm})$ & $77 \cdot 91$ & $10 \cdot 31$ & $79 \cdot 18$ & $10 \cdot 16$ & * \\
\hline Total physical activity (range 0-64) & $15 \cdot 14$ & $6 \cdot 39$ & $14 \cdot 69$ & $6 \cdot 10$ & NS \\
\hline \multirow[t]{2}{*}{ Age to peak height velocity (years) } & $-2 \cdot 43$ & 0.55 & $-2 \cdot 12$ & $0 \cdot 43$ & $* * *$ \\
\hline & \multicolumn{2}{|c|}{ Boys ( $n 321)$} & \multicolumn{2}{|c|}{ Girls (n 295) } & \\
\hline Sub-sample of those who had early life experience data & Mean & SD & Mean & SD & \\
\hline \multirow[t]{2}{*}{ Maternal BMI $\left(\mathrm{kg} / \mathrm{m}^{2}\right)$} & $23 \cdot 86$ & $4 \cdot 71$ & $24 \cdot 07$ & $5 \cdot 04$ & NS \\
\hline & $n$ & $\%$ & $n$ & $\%$ & \\
\hline \multicolumn{6}{|l|}{ Birth order } \\
\hline 1 & 203 & $63 \cdot 24$ & 193 & $65 \cdot 42$ & NS \\
\hline \multicolumn{6}{|l|}{ Maternal education } \\
\hline$\leq$ High school & 85 & $26 \cdot 48$ & 68 & $23 \cdot 05$ & NS \\
\hline \multicolumn{6}{|l|}{ Family living status } \\
\hline Two-parent household & 274 & $85 \cdot 36$ & 243 & $82 \cdot 37$ & NS \\
\hline
\end{tabular}

DASH, Dietary Approaches to Stop Hypertension; CFG, Canada's Food Guide.

$P$ values were calculated for continuous variables using the Student $t$ test and for categorical variables using the Fisher exact test: ${ }^{\star} P<0.05$, ${ }^{\star \star} P<0 \cdot 001$, ${ }^{\star * \star} P<0.0001$. 
Table 2 Results of regression models of the CFG index $v$. measures of body composition in the boys and girls who were recruited from schools within the Niagara region and assessed between September 2007 and June 2008†

\begin{tabular}{|c|c|c|c|c|c|c|}
\hline & \multicolumn{3}{|c|}{ Boys ( $n 788)$} & \multicolumn{3}{|c|}{ Girls (n 782) } \\
\hline & $b$ & $95 \% \mathrm{Cl}$ & $P$ value & $b$ & $95 \% \mathrm{Cl}$ & $P$ value \\
\hline \multicolumn{7}{|l|}{ BMI $\left(\mathrm{kg} / \mathrm{m}^{2}\right)$} \\
\hline Model $1 \neq$ & -0.02 & $-0.07,0.03$ & NS & -0.07 & $-0.12,-0.02$ & * \\
\hline Model $2 \S$ & -0.03 & $-0.07,0.02$ & NS & -0.04 & $-0.08,-0.002$ & * \\
\hline Model 3\| & -0.02 & $-0.06,0.03$ & NS & -0.04 & $-0.08,0.005$ & NS \\
\hline Model 4ণ & -0.01 & $-0.07,0.06$ & NS & -0.002 & $-0.07,0.07$ & NS \\
\hline \multicolumn{7}{|c|}{ Waist-to-height ratio } \\
\hline Model $1 \ddagger$ & -0.001 & $-0.001,0.0002$ & NS & -0.002 & $-0.002,-0.001$ & $\star \star \star \star ~$ \\
\hline Model $2 \S$ & -0.001 & $-0.001,0.0001$ & NS & -0.001 & $-0.002,-0.001$ & ** \\
\hline Model 3\| & -0.0005 & $-0.001,0.0003$ & NS & -0.001 & $-0.002,-0.0004$ & ** \\
\hline Model 4థ & -0.0004 & $-0.002,0.001$ & NS & -0.001 & $-0.001,0.0005$ & NS \\
\hline \multicolumn{7}{|c|}{ Waist-to-hip ratio } \\
\hline Model $1 \ddagger$ & -0.0003 & $-0.001,0.0005$ & NS & -0.002 & $-0.002,-0.001$ & $\star \star \star \star ~$ \\
\hline Model $2 \S$ & -0.0003 & $-0.001,0.0004$ & NS & -0.001 & $-0.002,-0.001$ & 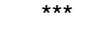 \\
\hline Model 3\| & -0.0002 & $-0.001,0.001$ & NS & -0.001 & $-0.002,-0.001$ & $\star \star \star *$ \\
\hline Model 4థ & 0.0001 & $-0.001,0.001$ & NS & -0.001 & $-0.002,0.0002$ & NS \\
\hline \multicolumn{7}{|l|}{ Waist girth } \\
\hline Model 1‡ & -0.07 & $-0.20,0.07$ & NS & -0.26 & $-0.38,-0.14$ & 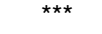 \\
\hline Model $2 \S$ & -0.09 & $-0.21,0.03$ & NS & $-0 \cdot 20$ & $-0.31,-0.09$ & ** \\
\hline Model 3\| & -0.05 & $-0.18,0.07$ & NS & -0.18 & $-0.30,-0.07$ & * \\
\hline Model 4థ & -0.07 & $-0 \cdot 25,0 \cdot 11$ & NS & $-0 \cdot 11$ & $-0 \cdot 29,0.07$ & NS \\
\hline \multicolumn{7}{|l|}{ Hip girth } \\
\hline Model $1 \ddagger$ & -0.05 & $-0.17,0.07$ & NS & $-0 \cdot 13$ & $-0.25,-0.02$ & * \\
\hline Model $2 \S$ & -0.07 & $-0.17,0.04$ & NS & $-0 \cdot 10$ & $-0.21,0.02$ & NS \\
\hline Model 3\| & -0.04 & $-0.15,0.07$ & NS & -0.08 & $-0.19,0.04$ & NS \\
\hline Model 4థ & -0.08 & $-0.25,0.08$ & NS & -0.03 & $-0 \cdot 21,0 \cdot 16$ & NS \\
\hline
\end{tabular}

CFG, Canada's Food Guide.

${ }^{*} P<0.05,{ }^{* *} P<0.001,{ }^{* \star *} P<0.0001$.

tMultiple linear regression analyses were conducted using SAS version 9.2 (SAS Institute Inc., Cary, NC, USA). The parameter estimate (b) represents the change in the body composition variable per one unit increase in the CFG index.

¥Model 1: unadjusted.

\$Model 2: adjusted for age to peak height velocity (aPHV).

$\|$ Model 3: adjusted for aPHV and total physical activity.

TModel 4: analysis on a sub-sample of children for whom early life experience data were available (321 boys; 295 girls). Model was adjusted for aPHV, total physical activity, birth order, parental BMI, parental education and marital status.

Table 3 Odds ratios (95\% confidence intervals) of overweight for tertile of the CFG index in the boys and girls who were recruited from schools within the Niagara region and assessed between September 2007 and June 2008†

\begin{tabular}{|c|c|c|c|c|c|c|c|c|c|c|c|c|}
\hline \multirow[b]{2}{*}{ Model } & \multicolumn{6}{|c|}{ Boys ( $n 788)$} & \multicolumn{6}{|c|}{ Girls (n 782) } \\
\hline & OR & $95 \% \mathrm{Cl}$ & $\mathrm{T} 1$ & T2 & T3 & $P$ value for trend & OR & $95 \% \mathrm{Cl}$ & T1 & T2 & T3 & $P$ value for trend \\
\hline Model 1‡ & 0.92 & $0 \cdot 77,1 \cdot 10$ & $1 \cdot 00$ & 0.90 & $0 \cdot 84$ & $0 \cdot 3642$ & $0 \cdot 82$ & $0.68,0.997$ & $1 \cdot 00$ & 0.98 & 0.67 & 0.0461 \\
\hline Model $2 \S$ & 0.89 & $0.73,1.08$ & $1 \cdot 00$ & 0.89 & $0 \cdot 79$ & $0 \cdot 2264$ & $0 \cdot 91$ & $0 \cdot 73,1 \cdot 12$ & $1 \cdot 00$ & $1 \cdot 21$ & $0 \cdot 81$ & $0 \cdot 3604$ \\
\hline Model 3॥ & 0.93 & $0 \cdot 76,1 \cdot 14$ & $1 \cdot 00$ & 0.96 & $0 \cdot 87$ & 0.4762 & 0.91 & $0 \cdot 73,1 \cdot 13$ & $1 \cdot 00$ & $1 \cdot 21$ & $0 \cdot 81$ & 0.3893 \\
\hline Model 4 & 0.93 & $0.66,1.31$ & $1 \cdot 00$ & 0.74 & 0.87 & 0.6692 & $1 \cdot 14$ & $0.78,1 \cdot 67$ & 1.00 & $1 \cdot 83$ & $1 \cdot 35$ & 0.4900 \\
\hline
\end{tabular}

CFG, Canada's Food Guide; T1, tertile 1; T2, tertile 2; T3, tertile 3.

tBMI was used to model the probability of overweight. BMI cut-offs were age- and gender-specific and corresponded to the widely used cut-off point of $25 \mathrm{~kg} / \mathrm{m}^{2}$ for adult overweight ${ }^{(17)}$. T1 of the CFG index was used as the reference group in the logistic regression model where T1 $<40$, T2 $\geq 40<46$ and T3 $\geq 46$. All analyses were conducted using SAS version $9 \cdot 2$ (SAS Institute Inc., Cary, NC, USA).

†Model 1: unadjusted.

$\S$ Model 2: adjusted for age to peak height velocity (aPHV).

$\|$ Model 3: adjusted for aPHV and total physical activity.

-Model 4: analysis on sub-sample of children for whom early life experience data were available (321 boys; 295 girls). Model was adjusted for aPHV, total physical activity, birth order, parental BMI, parental education and marital status.

analyses conducted on the sub-sample of children for whom early life experience data were available, the findings were similar. No association was observed between the CFG index and measures of adiposity after full adjustment in either girls or boys. A higher DASH index was, however, associated with reduced WG and reduced risk of OW in boys and with reduced BMI, WHtR, WHR and WG in girls. The results of both the main and the sub-sample analyses suggest that although adherence to the CFG is associated with certain measures of adiposity for girls, adherence to the DASH diet may be an effective means by which to reduce the risk of OW in both peri-adolescent boys and girls. 
Table 4 Results of regression models of the DASH index $v$. measures of body composition in the boys and girls who were recruited from schools within the Niagara region and assessed between September 2007 and June 2008†

\begin{tabular}{|c|c|c|c|c|c|c|}
\hline & \multicolumn{3}{|c|}{ Boys ( $n 788)$} & \multicolumn{3}{|c|}{ Girls (n 782) } \\
\hline & $b$ & $95 \% \mathrm{Cl}$ & $P$ value & $b$ & $95 \% \mathrm{Cl}$ & $P$ value \\
\hline \multicolumn{7}{|l|}{ BMI $\left(\mathrm{kg} / \mathrm{m}^{2}\right)$} \\
\hline Model 1‡ & -0.06 & $-0.10,-0.03$ & ** & -0.09 & $-0.12,-0.06$ & $\star * *$ \\
\hline Model $2 \S$ & -0.05 & $-0.08,-0.02$ & ** & -0.07 & $-0.10,-0.04$ & 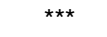 \\
\hline Model 3\| & -0.05 & $-0.08,-0.02$ & * & -0.07 & $-0 \cdot 10,-0.04$ & $* * *$ \\
\hline Model 4 & -0.03 & $-0.08,0.01$ & NS & -0.05 & $-0.09,-0.001$ & * \\
\hline \multicolumn{7}{|c|}{ Waist-to-height ratio } \\
\hline Model $1 \ddagger$ & -0.001 & $-0.002,-0.001$ & $\star \star \star \star ~$ & -0.002 & $-0.002,-0.001$ & $\star \star \star \star ~$ \\
\hline Model $2 \S$ & -0.001 & $-0.002,-0.001$ & $* * *$ & -0.001 & $-0.002,-0.001$ & $\star * *$ \\
\hline Model 3॥ & -0.001 & $-0.002,-0.0004$ & ** & -0.001 & $-0.002,-0.001$ & $* * *$ \\
\hline Model 4 & -0.001 & $-0.002,0.00001$ & NS & -0.001 & $-0.001,-0.0001$ & * \\
\hline \multicolumn{7}{|c|}{ Waist-to-hip ratio } \\
\hline Model $1 \ddagger$ & -0.001 & $-0.001,-0.0001$ & * & -0.001 & $-0.002,-0.001$ & 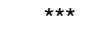 \\
\hline Model $2 \S$ & -0.001 & $-0.001,-0.0001$ & * & -0.001 & $-0.0002,-0.001$ & $\star \star \star *$ \\
\hline Model 3\| & -0.001 & $-0.001,-0.00004$ & * & -0.001 & $-0.002,-0.001$ & $\star \star \star *$ \\
\hline Model 4థ & -0.0004 & $-0.001,0.0004$ & NS & -0.001 & $-0.002,-0.0002$ & * \\
\hline \multicolumn{7}{|l|}{ Waist girth } \\
\hline Model $1 \ddagger$ & $-0 \cdot 20$ & $-0.29,-0.11$ & $\star \star \star \star ~$ & -0.28 & $-0.36,-0.20$ & $\star \star \star \star ~$ \\
\hline Model $2 \S$ & $-0 \cdot 17$ & $-0.25,-0.09$ & 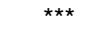 & $-0 \cdot 24$ & $-0.32,-0.17$ & 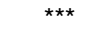 \\
\hline Model 3॥ & $-0 \cdot 15$ & $-0.24,-0.07$ & $* *$ & $-0 \cdot 24$ & $-0.31,-0.16$ & $\star * *$ \\
\hline Model 4؟ & $-0 \cdot 13$ & $-0.24,-0.008$ & * & $-0 \cdot 17$ & $-0.29,-0.05$ & * \\
\hline \multicolumn{7}{|l|}{ Hip girth } \\
\hline Model $1 \ddagger$ & $-0 \cdot 16$ & $-0.24,-0.08$ & ** & $-0 \cdot 18$ & $-0.26,-0 \cdot 10$ & 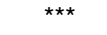 \\
\hline Model $2 \S$ & $-0 \cdot 13$ & $-0.20,-0.06$ & ** & $-0 \cdot 16$ & $-0.24,-0.08$ & $\star \star * *$ \\
\hline Model 3\| & $-0 \cdot 12$ & $-0.19,-0.04$ & * & $-0 \cdot 15$ & $-0.23,-0.07$ & $* *$ \\
\hline Model 4థ & $-0 \cdot 10$ & $-0 \cdot 21,0.006$ & NS & $-0 \cdot 10$ & $-0.22,-0.03$ & NS \\
\hline
\end{tabular}

DASH, Dietary Approaches to Stop Hypertension.

${ }^{\star} P<0.05,{ }^{* \star} P<0.001,{ }^{* \star \star} P<0.0001$.

tMultiple linear regression analyses were conducted using SAS version 9.2 (SAS Institute Inc., Cary, NC, USA). The parameter estimate (b) represents the change in the body composition variable per one unit increase in the DASH index.

†Model 1: unadjusted.

\$Model 2: adjusted for age to peak height velocity (aPHV).

IIModel 3: adjusted for aPHV and total physical activity.

-Model 4: analysis on sub-sample of children for whom early life experience data were available (321 boys; 295 girls). Model was adjusted for aPHV, total physical activity, birth order, parental BMI, parental education and marital status.

Table 5 Odds ratios (95\% confidence intervals) of overweight for tertile of the DASH index in the boys and girls who were recruited from schools within the Niagara region and assessed between September 2007 and June 2008†

\begin{tabular}{|c|c|c|c|c|c|c|c|c|c|c|c|c|}
\hline \multirow[b]{2}{*}{ Model } & \multicolumn{6}{|c|}{ Boys ( $n 788)$} & \multicolumn{6}{|c|}{ Girls ( $n 782)$} \\
\hline & OR & $95 \% \mathrm{Cl}$ & $\mathrm{T} 1$ & $\mathrm{~T} 2$ & T3 & $P$ value for trend & OR & $95 \% \mathrm{Cl}$ & $\mathrm{T} 1$ & T2 & T3 & $P$ value for trend \\
\hline Model $1 \ddagger$ & $0 \cdot 73$ & $0.61,0.88$ & $1 \cdot 00$ & $0 \cdot 80$ & 0.53 & 0.0010 & 0.68 & $0.56,0.82$ & 1.00 & 0.59 & $0 \cdot 47$ & $<0.0001$ \\
\hline Model $2 \S$ & 0.74 & $0.61,0.90$ & 1.00 & 0.75 & 0.54 & 0.0025 & 0.70 & $0.57,0.87$ & $1 \cdot 00$ & 0.76 & 0.49 & 0.0013 \\
\hline Model 3\| & 0.76 & $0.62,0.93$ & 1.00 & 0.77 & 0.58 & 0.0074 & 0.70 & $0.56,0.87$ & 1.00 & 0.76 & 0.48 & 0.0014 \\
\hline Model 4 & 0.71 & $0.50,0.99$ & 1.00 & 0.53 & 0.53 & 0.0462 & 0.86 & $0.59,1.25$ & $1 \cdot 00$ & $1 \cdot 17$ & 0.73 & 0.4268 \\
\hline
\end{tabular}

DASH, Dietary Approaches to Stop Hypertension; T1, tertile 1; T2, tertile 2; T3, tertile 3.

tBMI was used to model the probability of overweight. BMl cut-offs were age- and gender-specific and corresponded to the widely used cut off-point of $25 \mathrm{~kg} / \mathrm{m}^{2}$ for adult overweight ${ }^{(17)}$. T1 of the DASH index was used as the reference group in the logistic regression model where $\mathrm{T} 1<48, \mathrm{~T} 2 \geq 48<56$ and $\mathrm{T} 3 \geq 56$. All analyses were conducted using SAS version $9 \cdot 2$ (SAS Institute Inc., Cary, NC, USA).

$\ddagger$ Model 1: unadjusted.

\$Model 2: adjusted for age to peak height velocity (aPHV).

IIModel 3: adjusted for aPHV and total physical activity.

-Model 4: analysis on sub-sample of children for whom early life experience data were available (321 boys; 295 girls). Model was adjusted for aPHV, total physical activity, birth order, parental BMI, parental education and marital status.

To our knowledge, the present study is the first one to assess how conformity to the recommendations of both CFG and the DASH diet are associated with measures of body composition in a sample of youth from a schoolbased population. Two previous studies assessed the role of adherence to the DASH diet on measures of adiposity in a sample of youth with diabetes ${ }^{(20,25)}$. Neither study found an association between adherence to the DASH diet and measures of adiposity, although one of the studies did report that a higher adherence to the DASH diet was associated with a better lipid profile ${ }^{(25)}$. The lack of association between adherence to the DASH diet 
and measures of adiposity in these studies may have been a consequence of their sample being youths with diabetes - a population in which OW and obesity are highly prevalent ${ }^{(26)}$.

Conformity to the DASH diet may have been associated with more measures demonstrating decreased adiposity than conformity to the CFG due to the DASH diet's greater emphasis on fruit and vegetable intake. The DASH diet recommends four to five servings of fruit daily and four to five servings of vegetables daily (total of eight to ten servings), at an energy intake level of $8368 \mathrm{~kJ} / \mathrm{d}$ $(2000 \mathrm{kcal} / \mathrm{d})^{(9)}$, which is close to the average energy intake of our population $(9037 \mathrm{~kJ} / \mathrm{d}(2160 \mathrm{kcal} / \mathrm{d}))$. In contrast, CFG recommends six servings of fruits and/or vegetables daily for children aged 9 to 13 years ${ }^{(8)}$. Thus, those whose diets more closely conform to recommendations of the DASH diet may consume between two and four servings of fruits and vegetables more daily than those whose diets more closely conform to the recommendations of CFG. The hypothesis that the observed disparity between CFG and the DASH diet may be a result of the differences in the recommendations that each makes regarding the consumption of fruits and vegetables is supported by the findings of past studies, which have shown that increased consumption of fruits and vegetables is associated with decreased measures of adiposity $^{(14-16)}$. Foods high in soluble and insoluble fibre, such as fruits and vegetables, have been shown to reduce the risk of OW by being less energy dense than a comparable volume of food containing little or no dietary fibre ${ }^{(27,28)}$, by increasing satiety ${ }^{(29)}$, by decreasing the intestinal absorption of fat ${ }^{(27,30)}$ and/or by decreasing the intestinal absorption of carbohydrates which prevents sharp increases in postprandial insulin and thereby limits the storage of fat ${ }^{(31)}$. In light of these findings, CFG may be able to enhance its ability to reduce the risk of OW in peri-adolescence by increasing the recommended intake of fruits and vegetables.

Given that CFG and the DASH diet were designed for the maintenance of population health ${ }^{(7)}$ and for the management of hypertension in adults ${ }^{(9)}$, respectively, rather than for the management of body weight in children, caution must be taken before existing food guidelines are modified. Indeed, more research is required before either diet is prescribed to children as a means of managing body weight. Specifically, it is suggested that prospective studies be conducted to determine if adherence to either diet will reduce adiposity and/or prevent OW. In terms of the DASH diet, because it was designed specifically for use in adults, before it is used as a method of preventing or treating OW in children, studies will need to be conducted in order to verify that it meets the dietary needs of a growing population. Furthermore, even after the value of the diet in managing body weight is established and the adequacy of meeting the dietary needs of children is verified, before the DASH diet is used by public health policy makers to make dietary recommendations, it is suggested that the presentation of the dietary recommendations be tailored to the target population. For example, in order to increase the amenability of the DASH diet to adolescents, presenting the recommended daily intakes of each food group by age category, as is done by CFG, rather than by estimated daily energy requirements may be of value.

In addition, there are several limitations to the present study. First, due to the cross-sectional study design, conclusions regarding causation cannot be drawn. Second, many parents did not return the parental questionnaire resulting in a dramatic drop in sample size from the main analysis to the sub-sample analysis. Although there were no major differences between those who were included in the sub-sample analysis and those who were not in terms of the main characteristics, because those who were included reported being slightly more physically active and had slightly smaller BMI, WHtR, WG and HG measures, the sub-sample results may underestimate the true association. There are several strengths of the study including that the sample was from a school-based population, dietary data were collected using a validated questionnaire, and body composition was assessed by trained research assistants.

\section{Conclusion}

The results of the present study indicate that diets that conform to the recommendations of CFG are associated with reduced measures of adiposity among girls; whereas diets that conform to recommendations of the DASH diet are associated with reduced measures of adiposity among girls and boys. These findings suggest that following the DASH diet may prevent OW in peri-adolescents. Before the DASH diet is prescribed to peri-adolescents as a means of preventing and/or treating OW, however, prospective research is needed to verify that adherence to the diet will reduce adiposity and/or prevent OW and that the diet will also meet the dietary needs of a growing population.

\section{Acknowledgements}

The study was funded by the Canadian Institutes of Health Research (grant number: 171577) and the Social Sciences and Humanities Research Council of Canada (grant number: 410-2007-1770). There are no conflicts of interest. All authors contributed substantially to the conception and design of the study, the acquisition, analysis and interpretation of data, have drafted the article or revised it critically for important intellectual content. The authors would like to thank the District School Board of Niagara, students and their parents for their support of the study. 


\section{Supplementary Materials}

For Supplementary Materials for this article, please visit http://dx.doi.org/10.1017/S1368980012001024

\section{References}

1. Raine KD (2004) Overweight and Obesity in Canada: A Population Health Perspective. Ottawa: Canadian Institute for Health Information.

2. Tremblay MS, Katzmarzyk PT \& Willms JD (2002) Temporal trends in overweight and obesity in Canada, 1981-1996. Int J Obes Relat Metab Disord 26, 538-543.

3. Must A \& Strauss RS (1999) Risks and consequences of childhood and adolescent obesity. Int J Obes Relat Metab Disord 23, Suppl. 2, S2-S11.

4. Grotle M, Hagen KB, Natvig B et al. (2008) Obesity and osteoarthritis in knee, hip and/or hand: an epidemiological study in the general population with 10 years follow-up. BMC Musculoskelet Disord 9, 132.

5. McKinnon RA, Orleans CT, Kumanyika SK et al. (2009) Considerations for an obesity policy research agenda. $\mathrm{Am} \mathrm{J}$ Prev Med 36, 351-357.

6. Lobstein T, Baur L \& Uauy R (2004) Obesity in children and young people: a crisis in public health. Obes Rev $\mathbf{5}$ Suppl. 1, 4-104.

7. Health Canada (2009) Food and nutrition: what is Health Canada doing? http://www.hc-sc.gc.ca/fn-an/index-eng. php (accessed June 2010).

8. Health Canada (2007) Eating well with Health Canada's Food Guide. http://www.hc-sc.gc.ca/fn-an/alt_formats/hpfbdgpsa/pdf/food-guide-aliment/view_eatwell_vue_bienmangeng.pdf (accessed June 2010).

9. US Department of Health and Human Services, National Institutes of Health \& National Heart, Lung, and Blood Institute (2006) Your Guide to Lowering Your Blood Pressure with DASH. NIH Publication no. 06-4082. Bethesda, MD: NIH.

10. Sacks FM, Obarzanek E, Windhauser MM et al. (1995) Rationale and design of the Dietary Approaches to Stop Hypertension trial (DASH). A multicenter controlledfeeding study of dietary patterns to lower blood pressure. Ann Epidemiol 5, 108-118.

11. Azadbakht L, Fard NR, Karimi M et al. (2011) Effects of the Dietary Approaches to Stop Hypertension (DASH) eating plan on cardiovascular risks among type 2 diabetic patients: a randomized crossover clinical trial. Diabetes Care 34, 55-57.

12. Svetkey LP, Simons-Morton D, Vollmer WM et al. (1999) Effects of dietary patterns on blood pressure: subgroup analysis of the Dietary Approaches to Stop Hypertension (DASH) randomized clinical trial. Arch Intern Med 159, 285-293.

13. Centers for Disease Control and Prevention (2009) Obesity - halting the epidemic by making health easier: At a Glance 2009. http://www.cdc.gov/nccdphp/publications/ AAG/pdf/obesity.pdf (accessed June 2010).
14. Bes-Rastrollo M, Martinez-Gonzalez MA, Sanchez-Villegas A et al. (2006) Association of fiber intake and fruit/ vegetable consumption with weight gain in a Mediterranean population. Nutrition 22, 504-511.

15. Epstein LH, Gordy CC, Raynor HA et al. (2001) Increasing fruit and vegetable intake and decreasing fat and sugar intake in families at risk for childhood obesity. Obes Res $\mathbf{9}$, 171-178.

16. Sartorelli DS, Franco LJ \& Cardoso MA (2008) High intake of fruits and vegetables predicts weight loss in Brazilian overweight adults. Nutr Res 28, 233-238.

17. Cole TJ, Bellizzi MC, Flegal KM et al. (2000) Establishing a standard definition for child overweight and obesity worldwide: international survey. BMJ 320, 1240-1243.

18. Rockett HR, Wolf AM \& Colditz GA (1995) Development and reproducibility of a food frequency questionnaire to assess diets of older children and adolescents. J Am Diet Assoc 95, 336-340.

19. Rockett HR, Breitenbach M, Frazier AL et al. (1997) Validation of a youth/adolescent food frequency questionnaire. Prev Med 26, 808-816.

20. Gunther AL, Liese AD, Bell RA et al. (2009) Association between the dietary approaches to hypertension diet and hypertension in youth with diabetes mellitus. Hypertension 53, 6-12.

21. Liese AD, Nichols M, Sun X et al. (2009) Adherence to the DASH Diet is inversely associated with incidence of type 2 diabetes: the insulin resistance atherosclerosis study. Diabetes Care 32, 1434-1436.

22. Liese AD, Schulz M, Moore CG et al. (2004) Dietary patterns, insulin sensitivity and adiposity in the multi-ethnic Insulin Resistance Atherosclerosis Study population. $\mathrm{Br} J$ Nutr 92, 973-984.

23. Hay J (1992) Adequacy in and predilection for physical activity in children. Clin J Sport Med 2, 10.

24. Mirwald RL, Baxter-Jones AD, Bailey DA et al. (2002) An assessment of maturity from anthropometric measurements. Med Sci Sports Exerc 34, 689-694.

25. Liese AD, Bortsov A, Gunther AL et al. (2011) Association of DASH diet with cardiovascular risk factors in youth with diabetes mellitus: the SEARCH for Diabetes in Youth study. Circulation 123, 1410-1417.

26. Liu LL, Lawrence JM, Davis C et al. (2010) Prevalence of overweight and obesity in youth with diabetes in USA: the SEARCH for Diabetes in Youth study. Pediatr Diabetes 11, $4-11$.

27. Slavin JL (2005) Dietary fiber and body weight. Nutrition 21, 411-418.

28. van Dam RM \& Seidell JC (2007) Carbohydrate intake and obesity. Eur J Clin Nutr 61, Suppl. 1, S75-S99.

29. Raben A, Christensen NJ, Madsen J et al. (1994) Decreased postprandial thermogenesis and fat oxidation but increased fullness after a high-fiber meal compared with a low-fiber meal. Am J Clin Nutr 59, 1386-1394.

30. Heaton KW (1973) Food fibre as an obstacle to energy intake. Lancet 2, 1418-1421.

31. Brennan CS (2005) Dietary fibre, glycaemic response, and diabetes. Mol Nutr Food Res 49, 560-570. 